Como citar este artículo en APA: Pardo Farina, F. (2019). Influencia de algunos aspectos de la filosofía política de Aristóteles en la Prima Clementis. Cuestiones Teológicas, 46 (105), 125-147. doi: http://dx.doi.org/10.18566/cueteo.v46n105.a05

\title{
INFLUENCIA DE ALGUNOS ASPECTOS DE LA FILOSOFÍA POLÍTICA DE ARISTÓTELES EN LA PRIMA CLEMENTIS $^{1}$
}

Influence of Some Aspects of Aristotle's Political Philosophy on Prima Clementis

Influência de alguns aspectos da filosofia política de aristóteles na Prima Clementis

\author{
Felipe Gonzalo Pardo Fariña ${ }^{2}$
}

1 Este artículo hace parte de la tesis doctoral en filosofía que lleva por título: 'La filosofía del cristianismo primitivo romano. Presencia de la filosofía de Aristóteles y de algunos estoicos, recepcionada por el proyecto educativo romano, en la filosofía del primer escrito cristiano romano: la Prima Clementis'. Se sustentó en la Pontificia Universidad Católica de Chile y en un proyecto Conicyt 2013-2017.

2 Doctor en Teología y Filosofía por la Pontificia Universidad de la Santa Cruz, Italia. Profesor de la Pontificia Universidad Católica de Chile (Chile). Correo electrónico: fpardo@uc.cl 


\section{Resumen}

Pretendo mostrar en el presente estudio la recepción que hace la Prima Clementis, exhortación cristiana romana de la segunda mitad del siglo I d.C., de algunos aspectos de la filosofía política de Aristóteles. El método hacia dicho objetivo se recorre mediante el análisis e interpretación de los vocablos óuóvoı́ (concordia) y otóoıs (discordia) en algunos textos de la Etica a Nicómaco, Etica Eudemia y Prima Clementis. Concluyo que la Prima Clementis utiliza

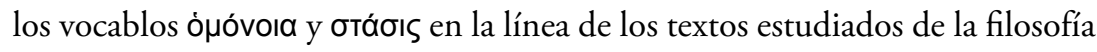
política de Aristóteles. Dicha cercanía permite enunciar como hipótesis que el autor de la Prima Clementis tuvo un contacto con la obra de Aristóteles mediante Quintiliano, creador del proyecto educativo romano confeccionado en la segunda mitad del siglo I d.C. en Roma.

Palabras clave: ójóvoıa, oтáoıs, Ética a Nicómaco, Ética Eudemia, Prima Clementis.

\section{Abstract}

In this article, my purpose is to show the reception of some aspects of Aristotle's political philosophy within Prima Clementis, a roman Christian exhortation of the second half of the first century A.D. Methodologically, I undertake an analysis of and put an interpretation on the concepts ómóvora (concord) and бтóoıs (discord) in some passages of Nicomachean Ethics, Eudemian Ethics and Prima Clementis. I conclude that Prima Clementis uses both ónóvoı́ and бтóoıৎ in the same sense of Aristotle's political philosophy. Such closeness makes possible to put forward the hypothesis (which I consider in another work) that the author of Prima Clementis had contact with Aristotle's work through Quintilian, who was the developer of the roman education project that was conceived during the second half of the first century A.D.

Key Words: òjóvoıa, oráoıs, Nicomachean Ethics, Eudemian Ethics, Prima Clementis. 


\section{Resumo}

Nesse estudo busco estabelecer a recepção que faz a Prima Clementis exortação cristã romana da segunda metade do século I d. C.- de alguns aspetos da filosofia politica de Aristóteles. Para conseguir esse objetivo se propôe uma análise e uma interpretação dos vocábulos ópóvoı (concórdia) e oTáoıs (discórdia) numa seleção de textos da Ética a Nicómaco, Ética Eudemia e Prima Clementis. Concluo que a Prima Clementis utiliza os vocábulos ómóvoı e ơó́ııs na perspectiva dos textos tratados pela filosofia politica de Aristóteles. Essa abordagem permite enunciar como hipótese que o autor da Prima Clementis teve um contato com a obra de Aristóteles através de Quintiliano, o criador do projeto educativo romano que foi feito na segunda metade do século I d. C. em Roma.

Palavras-chave: ónóvoıa, oróoıs, Ética a Nicómaco, Ética Eudemia, Prima Clementis.

\section{Introducción}

Tanto el análisis como las interpretaciones del presente estudio convergen en los conceptos ópóvoıa (concordia) y бтóoıs (discordia) ${ }^{3}$, a partir de los cuales formulo una tesis que recorre las páginas del escrito y una hipótesis que la sustenta. La tesis afirma que el autor de la Prima Clementis utiliza ónóvoıa y oróoıs, entre otras acepciones, en la línea aristotélica de virtud política. Este enunciado se fundamenta en la estrecha relación que muestran los vocablos ónóvoı́ y otóoıs en la Prima Clementis (1Clem), Ética a Nicómaco (EN) y Ética Eudemia (EE), ${ }_{4}^{4}$ cuando se atiende a su dimensión

3 La narrativa del artículo conserva, en la mayoría de los casos, el término griego.

4 La selección de textos griegos de la Prima Clementis, Ética a Nicómaco y Ética Eudemia corresponde a la siguiente fuente: Aristóteles. Aristoteles Phil. et Corpus Aristolelicum, Ethica Nicomachea (EN) Ethica Eudemia (EE). En: Thesaurus linguae gracae (TLG). Edición digitalizada de textos escritos en griego desde Homero hasta 
social que liga al individuo con la comunidad o ciudad civil. La hipótesis que sustenta la tesis expuesta es: el autor de la Prima Clementis recepcionó algunos escritos de Aristóteles transmitidos por sus discípulos. La tesis y la hipótesis enunciadas se exponen en dos momentos: el primero, mediante la revisión de los vocablos ómóvoıa y oróoı en la Ética a Nicómaco y Ética Eudemia, rescatando su sentido filosófico-político; el segundo, mediante el análisis en la Prima Clementis de ơó́ı y òuóvoıa, cuya intención es mostrar que dichos términos tienen en este escrito un uso similar al que les confiere Aristóteles en su filosofía política.

\section{La ópóvoı́ y la oTáoıs en Aristóteles}

\section{La ójóvoı́a y la amistad}

La ópóvoı en la ética de Aristóteles se relaciona estrechamente con la temática de la amistad. Abordo las principales ideas que encierra el concepto de amistad en algunos textos que hallamos en la Ética a Nicómaco. La intención subyacente a dicha descripción es situar el concepto óróvoı en su contexto literario-filosófico. La amistad es, según el estagirita, una virtud (ética) o algo acompañado de virtud. ${ }^{5}$ Examinemos a continuación sus características.

En primer lugar, existe un desacuerdo acerca de la naturaleza de la amistad. En relación a su significado coexisten muchas opiniones. ${ }^{6}$ En segundo lugar, la amistad es necesaria para la vida y vale más que los recursos

la caída de Bizancio en el año 1453. Irvine: Universidad de California, 1972ss. Utilizo la traducción de J. Ayán para los textos de la Prima Clementis: Clemente de Roma. (1994). Clemente de Roma. Carta a los corintios. Homilía anónima (Secunda Clementis).(J. Ayán, Trad.). Madrid: Ciudad Nueva. Utilizo la traducción de Pallí Bonet para los textos de Aristóteles: Aristóteles, (1985). Ética Nicomaquea. Ética Eudemia. (J. Pallí Bonet, trad. Col. Biblioteca Clásica Gredos, 89). Madrid: Editorial Gredos.

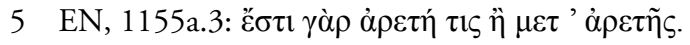

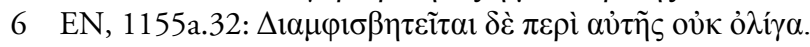


materiales: la existencia humana debe darse en compañía de los amigos. Al ser humano de nada le sirven las riquezas de este mundo si no posee amigos. ${ }^{7}$

En tercer lugar, entre la amistad y la posesión de bienes materiales existe compatibilidad y no oposición: tanto la posesión de bienes como su ausencia están relacionadas directamente con la obtención de los amigos. Efectivamente, los bienes materiales que coexisten con el hombre deben, según Aristóteles, ser compartidos con los amigos, quienes ayudan a conservarlos. La amistad se ejercita en los momentos de prosperidad y de adversidad: los amigos están capacitados para auxiliar a los jóvenes, a los viejos y a quienes se encuentran en la mejor etapa de su vida. A los jóvenes les preservan del error (en lo referente a posibles negocios), a los viejos los asisten en sus carencias, y a los que están en su mejor momento les apoyan para que puedan realizar sus nobles acciones. ${ }^{8}$

En cuarto lugar, la amistad para Aristóteles acontece de modo natural: se desarrolla sin intereses ni cálculos previos. Por lo tanto, la amistad es familiar, esto es, se da en la cordialidad del bien vivir: de modo espontáneo el hombre es amigo del hombre debido a que la amistad se despliega entre los hombres; de manera afable esta nace y crece entre las aves y entre la mayoría de los animales. El estagirita piensa que la amistad -entendida conforme a lo dicho- involucra al universo en la sana sociabilidad. ${ }^{9}$

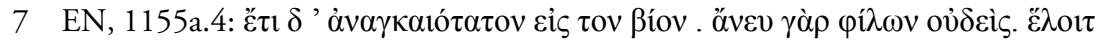
, $\grave{\alpha} v \zeta \tilde{\eta} v$.

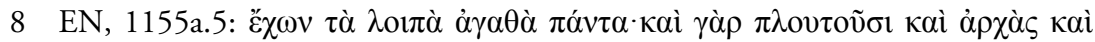

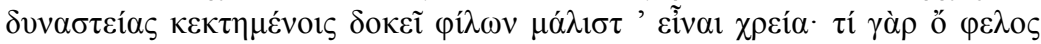

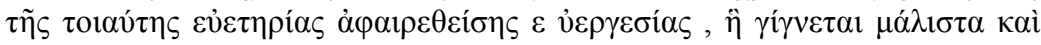

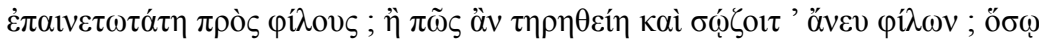

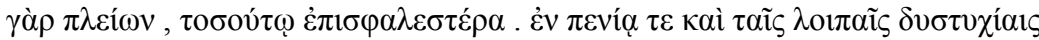

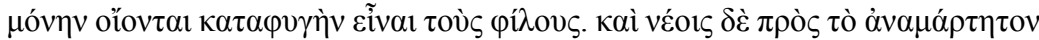

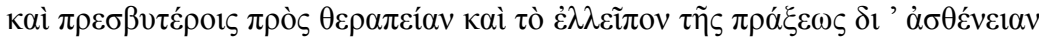

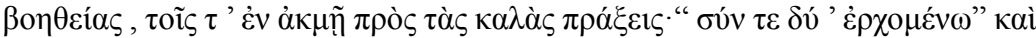

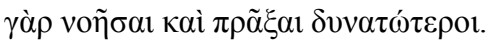

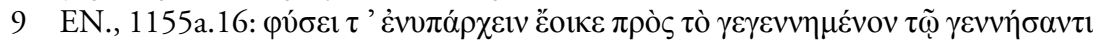

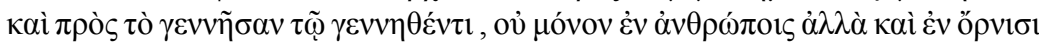

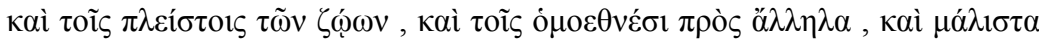

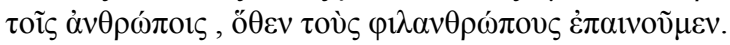


En quinto lugar, la amistad es algo hermoso cuando se vive en apertura sana y transparente a un otro mediante la donación y el recibimiento mutuo. El que cumple con la característica descrita de la amistad es un hombre bueno, que aspira a tener muchos y verdaderos amigos. ${ }^{10}$

En sexto lugar, la amistad es semejante a la ónóvoia ${ }^{11}$. En efecto, la amistad se vive en ónóvoı́, porque una de sus características es la 'concordia. ${ }^{12}$ Lo contrario a la amistad en la ómóvoı́, según Aristóteles, es la 'discordia' ${ }^{13}$. La vida en concordia conduce al hombre a la felicidad (Martí, 2017, p. 46). Con estas afirmaciones el estagirita nos introduce en la interpretación política de la ópóvoıa, la que abordo en el siguiente apartado.

\section{La ónóvoıa en la ciudad}

Se ha dicho en las líneas anteriores que la concordia está estrechamente relacionada con la amistad, sin ónóvoı́ no existe una amistad verdadera. Agrego a lo anterior que la amistad dada en la ómóvoı́ es una de las fortalezas éticas principales de la ciudad: esta debe regirse por la amistad verdadera entre los ciudadanos que la componen, de ahí que la ómóvoı́ es, en el decir de Aristóteles, una amistad política o civil (Gómez, 2017, p. 112). ${ }^{14}{ }^{\text {¿En qué }}$ consiste una amistad verdadera entre los ciudadanos basada en la ónóvoıa? Más que señalar una definición del concepto, en el siguiente apartado apunto a sus características. Inicialmente, Aristóteles piensa que dicha amistad ha de tener como característica principal el 'consenso..$^{15}$ Esto significa que la naturaleza de la ónóvoı́ está en relación directa con el acuerdo entre ciudadanos acerca de lo más conveniente para la ciudad:

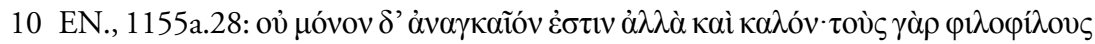

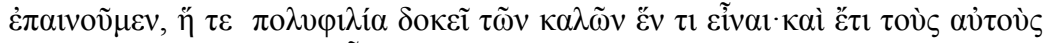

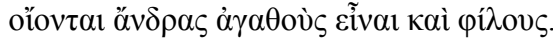

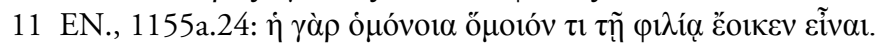

12 Traduzco en las líneas siguientes ó $\mu$ óvoı $\alpha$ como 'concordia'.

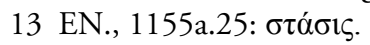

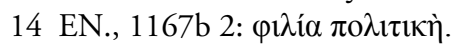

15 La expresión es mía e intenta sintetizar la explicación que viene a continuación. 
Así pues, la concordia parece ser una amistad civil, como se dice, pues está relacionada con lo que conviene y con lo que afecta a nuestra vida. Tal concordia existe en los hombres buenos, puesto que estos están de acuerdo consigo mismos y entre sí; teniendo lo mismo en la mente, por así decir (pues sus deseos son constantes y no fluctúan como las aguas en el Euripo) (EN, 1167b.2-7). ${ }^{16}$

A la característica principal de la amistad política algunos estudiosos agregan los siguientes rasgos: disposición interna y volitiva que involucra sentimientos favorables hacia el otro (Cadavid, 2011, p. 63); condiciones de igualdad, semejanza de virtud y reciprocidad (Giraldo, Díaz y López, 2017, p. 192); un mismo parecer en aquellas cosas que son prácticas e importantes para la comunidad (Motto, 2013, p. 38); amor entendido como afecto llevado a su grado supremo (Valencia, 2018, p. 14); reconocimiento, aceptación del otro, igualdad (Blanco y Parrado, 2018, p. 116); participación del ciudadano en modo directo de la función deliberativa en la ciudad, esto es, en los juicios encaminados al gobierno aun cuando no participe en una magistratura o cargo gubernamental (Bueno, 2018, p. 16).

La conveniencia de la ónóvoı́ política se funda en la recta razón. Lo conveniente observado desde la recta razón implica unanimidad de pensamiento entre los miembros de la ciudad. ¿Cómo se ejercita de modo concreto la unanimidad ciudadana de pensamiento? La descripción de su ejercicio se comprende mejor cuando nos fijamos, en primer lugar, en lo que no es la unanimidad ciudadana de pensamiento. Esta no consiste -según el estagirita- en que todos los miembros de la sociedad deban pensar lo mismo en materias concernientes a lo mejor o más conveniente para la ciudad, ya que lo más conveniente para la ciudad no es la uniformidad de criterio: esta existe entre los ciudadanos, pero se verifica en materias que son ajenas a lo conveniente para la ciudad, por ejemplo, en el conocimiento de la conformación del universo.

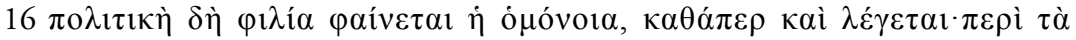

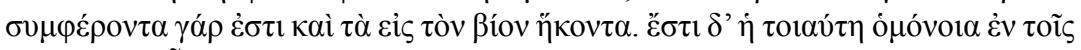

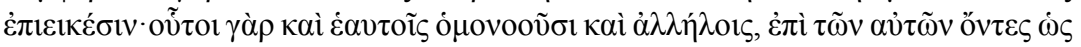

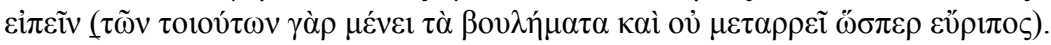


En este tipo de asuntos -según nuestro autor- no se admiten conclusiones parciales debidas a escorzos o puntos de vista opinables. Dichos argumentos se ordenan al conocimiento científico apodíctico y no a la acción que implica la virtud. La unanimidad ciudadana de pensamiento en contra de la uniformidad de criterio constituye un logro a partir de posturas que difieren entre sí, porque precisamente los ciudadanos se pronuncian en aquello que puede ser de otra manera. Dicho logro es el resultado de la deliberación a la luz de la recta razón, e implica un nivel de convivencia o amistad ciudadana más alto, es decir, con la capacidad de poner en tela de juicio la opinión personal acerca de lo que se discute. Comparto la reflexión de Godoy (2012) respecto a la consideración de la deliberación en la ciudad como un punto central de la democracia aristotélica:

En sus tratados éticos, Aristóteles centra su discurso acerca de la amistad política en el acuerdo o consenso al interior de la Polis. El filósofo observa que los amigos concuerdan entre sí, tienen la misma opinión sobre los asuntos de interés mutuo y aspiran a realizar todo aquello que es bueno para su vida en común y está al alcance de sus posibilidades. Algo similar ocurre en el nivel de la comunidad política y que el filósofo denomina concordia (homonoia). Según Aristóteles, esta, como modalidad de amistad, une a la comunidad en torno a aquello que concierne a la vida en común. Se trata de una actividad eminentemente práctica, a través de la cual la comunidad ejecuta decisiones políticas, compartidas por todos y que buscan beneficiar a todos. El filósofo observa que siendo la concordia un sentimiento amistoso, no es una simple igualdad de opiniones (homodoxía) (p. 358).

Alcanzar la unanimidad ciudadana de pensamiento en aquello que puede ser de otra manera requiere de amistad esforzada y dialógica. La ciudadanía -según el estagirita- puede llegar a un acuerdo o avenencia acerca de lo más conveniente para la ciudad después de un debate con altura de miras: la unanimidad ciudadana de pensamiento constituye una materia que admite libertad de opinión y requiere de una deliberación común conforme a la razón, porque lo más conveniente acoge distintos puntos de vista. Leamos lo expuesto desde el texto mismo de Aristóteles:

La concordia se parece, también, a lo amistoso, y por esta razón no es igualdad de opinión, pues ésta puede darse incluso en aquellos que no 
se conocen entre sí. Tampoco se dice que los que tienen los mismos pensamientos sobre cualquier cosa son unánimes, por ejemplo, los que piensan lo mismo sobre los fenómenos celestes (porque ser del mismo parecer sobre estas cosas no supone amistad) (EN, 1167a.22-26). ${ }^{17}$

Los ciudadanos eligen, luego de la deliberación conforme a la razón, las mismas cosas y realizan aquello que es de común interés. ${ }^{18}$

En algunos textos de la Ética Eudemia, Aristóteles expone un pensamiento similar a lo dicho en los párrafos anteriores:

Se cree, en efecto, que los amigos están de acuerdo y que los que concuerdan son amigos. Pero la concordia basada en el sentimiento amoroso no se extiende a todo, sino a los actos de las personas concordes y a las cosas que tienden a la vida común; y no es solamente un acuerdo en el pensamiento y en el deseo (porque es posible pensar y desear cosas contrarias, como vemos que existe esta discordancia en el incontinente), y si uno está de acuerdo (ònovocĩv) en la elección no tiene por qué estarlo también en el apetito. Entre los buenos existe la concordia (ónóvoı́); siendo así, por cierto, que los malos eligen y desean las mismas cosas y se perjudican unos a otros. Y la concordia (ònovoía), al igual que la amistad, parece que no se dice de una manera simple, sino que la primera es también por naturaleza buena, por lo cual no es posible que los malos estén así de acuerdo (ònovozĩv); pero hay otra clase, según la cual, incluso los malos concuerdan (ònovooũoıv), cuando eligen y desean las mismas cosas. Pero deben desear lo mismo, de

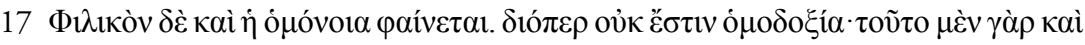

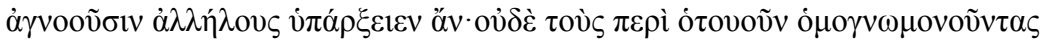

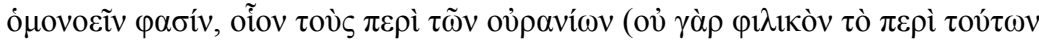
ó efecto, la apertura sana y transparente del sujeto a un otro enseña la bondad y belleza de la amistad, generando acuerdos de conciencia respecto a lo más conveniente para la ciudad.

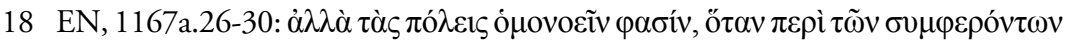

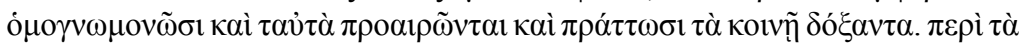

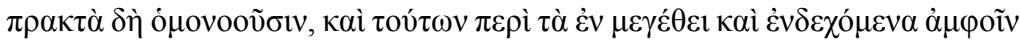

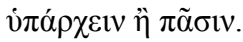


manera que ambos puedan poseer lo que desean, pues si el objeto del deseo es tal que no es posible que pertenezca a ambos, se pelearán; en cambio, los que están de acuerdo (oi ómovooũvtes) no se pelean. Hay, pues, concordia (ónóvoıa) cuando la elección es la misma tanto en lo que concierne al mandar como al obedecer, cada uno no escogiéndose a sí mismo, sino ambos escogiendo a la misma persona. En suma, la concordia (ónóvoıa) es la amistad política (EE, 1241a.15-34). ${ }^{19}$

Según la reflexión de algunos estudiosos, la deliberación ciudadana que propone Aristóteles es una condición irrenunciable de cohesión social (Sánchez, 2018, p. 35) que lleva a elegir lo mejor a la luz de la recta razón (Morales, 2003, p. 82) (Garcés y Giraldo, 2014, p.199), valorándose de este modo la deliberación política como parte integrante de la filosofía política (Gallardo, 2009, p. 90). La deliberación de lo bueno y mejor no solamente se atiene al ámbito de lo privado (lo bueno y mejor para mí) sino al ámbito público (lo bueno y lo mejor para la ciudad) (Zamora, 2001, p. 48). La deliberación se apoya en una técnica persuasiva, con el fin de convencer a las mayorías acerca de una determinada posición en algún asunto que admite ser tratado desde varios puntos de vista (Covarrubias, 2000, p. 271). Deliberar es una correcta elección frente a las distintas posibilidades que toda experiencia de lo contingente presenta (Borisonik, 2011, p. 110), y una virtud que debe ostentar cualquier ciudadano en toda polis bien constituida (de Meza, 2012, p. 197).

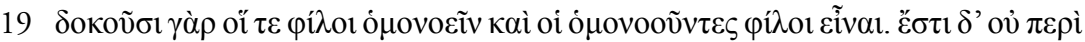

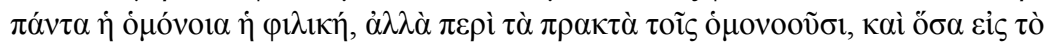

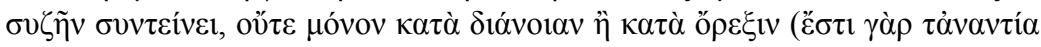

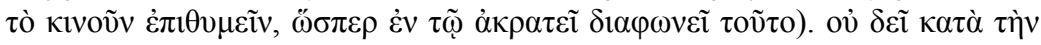

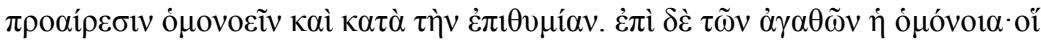

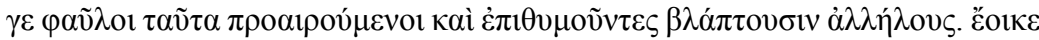

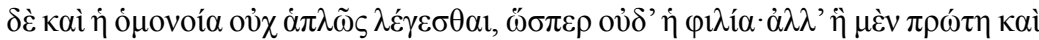

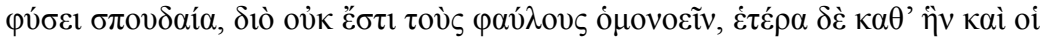

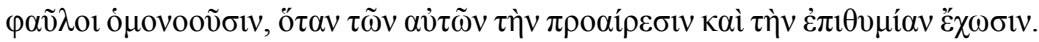

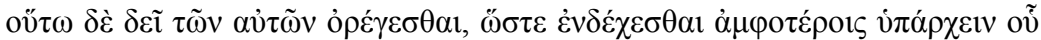

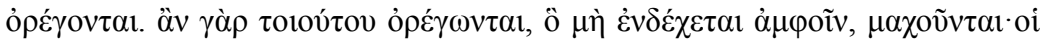

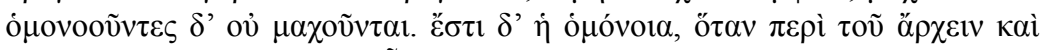

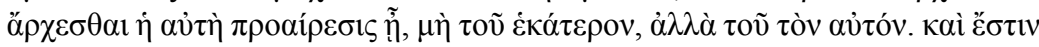

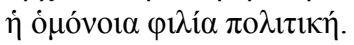




\section{La ơóoıs en la ciudad}

La unanimidad ciudadana de pensamiento se pone en situación de riesgo -según Aristóteles- cuando se manifiesta la oróoıı o discordia al interno de la comunidad civil. ¿En qué consiste dicha actitud? Radica en la imposición del particular punto de vista, es decir, en el deseo de hacer prevalecer una determinada visión acerca de un problema sin el recurso del diálogo. La motivación que tiene quien incurre en oróolৎ es la pretensión de dominio sobre los demás hombres. Dicha pretensión, a diferencia de la ónóvoıa, es una manera de ser y de vivir que insta a la discordia y promueve la enemistad. ${ }^{20}$ Los ciudadanos que fomentan la oróøı - a diferencia de aquellos que realizan el ideal de la ómóvoı́- no buscan lo conveniente ni viven en la amistad; solo concuerdan entre ellos en una medida pequeña en torno a ciertos asuntos ${ }^{21}$.

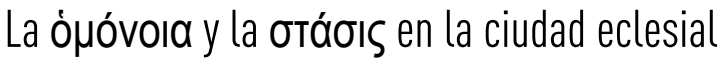 según la Prima Clementis}

La Prima Clementis es el primer escrito cristiano de seguro origen romano (Prinzivalli, 2009, p. 23). Es probable que sea una exhortación de parte de la Iglesia de Roma a la Iglesia de Corinto escrita en modo homilía. Es un texto de notable espesor literario y articulación retórica ${ }^{22}$ en la solución de

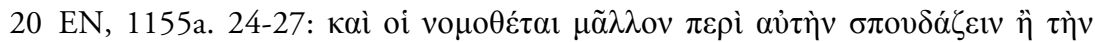

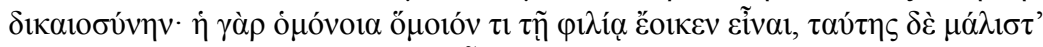

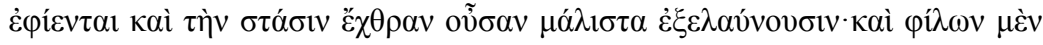

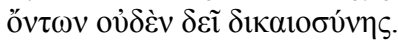

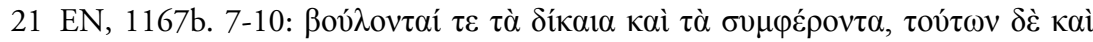

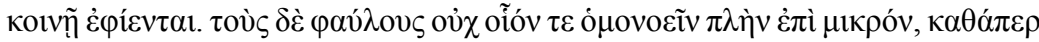

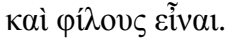

Estoy de acuerdo con los estudiosos (Farrés, 2015, p.41) que piensan la amistad aristotetélica basada en la concordia como algo muy importante en el contexto de la filosofia política. La concordia aristotélica está en estrecha relación con la amistad cívica: ambas actúan directamente en la conservación de la estabilidad y unidad de la ciudad. La concordia -según Aristóteles- es una propuesta necesaria frente a la lucha motivada por intereses partidistas.

22 (Pardo, 2019, p. 14 con bibliografía). 
un conflicto acontecido en Corinto, cuya naturaleza se mueve en el campo de las hipótesis más o menos probables (Bakke, 2001, pp. XVI-390). ${ }^{23}$

La expresión óhóvoı́, sin antecedentes en el mundo de la literatura cristiana de la época, ingresa en el cristianismo mediante la Prima Clementis. ¿Qué ascendencia cultural se reconoce en este término? Según varios estudiosos recopilados por Martín (1994, pp. 64-67) el cristianismo romano de la primera centuria es receptor de una vasta gama literaria de procedencia diversa en cuyos textos se utiliza el vocablo ónóvoı́. Destacan, entre estas obras, tanto la Septuaginta como algunos escritos estoicos y del filósofo Filón de Alejandría. Mostraré en las líneas siguientes, mediante un análisis de los contextos literarios, la utilización que hace del binomio ómóvoı́-бróoıs el autor de la Prima Clementis con el objetivo de establecer una conexión entre ambos términos y la filosofía política de Aristóteles, estudio no realizado hasta la fecha.

El término ónóvoı (concordia) aparece catorce veces en la Prima Clementis. $^{24}$

En primer lugar y en perspectiva teológica, la ómóvola es, según la Prima Clementis, la comunión en los sentimientos realizada por los miembros de la comunidad eclesial, la que invoca a una sola voz la presencia divina en la celebración del culto. Esta acepción del término se refiere a la reunión de los miembros de la Iglesia en concordia, quienes piden a Dios que haga partícipes a los allí reunidos de sus grandes y gloriosas promesas. La interpretación de óuóvoı en contexto cultual habla de una cierta unidad eclesial que, en cuanto cuerpo u organismo, acude al culto divino con

23 Coincido con Bakke en que la Prima Clementis proporciona una cierta información acerca de lo que acontece en la Iglesia de Corinto en los márgenes de la primera centuria cristiana. La naturaleza del conflicto en Corinto se relaciona con personas de diferente nivel socio económico: de una parte, los presbíteros, quienes ostentan dicho poder; de otra, los laicos, quienes están sometidos a ciertas cargas económicas que les imponen los presbíteros, lo cual les conduce a la sedición.

24 La estadística según (Pardo, 1988:38) se constata desde varias investigaciones. Las expresiones 'estar de acuerdo' y 'estar en concordia' son las formas verbales que mejor traducen el verbo ó $\mu$ óvoєĩv. 
emplazamiento en Roma. ${ }^{25}$ A lo anterior se suma la presencia de otros textos donde se encuentra el vocablo ò óvoı también en un contexto cultual. ${ }^{26}$

En efecto, tanto el pasaje de 1Clem, 60, 4 como el de 1Clem, 61, 1 se ubican en el marco de oración que se ofrece a Dios en la ciudad eclesial romana. Existe una duda acerca de si ambos pasajes apelan exclusivamente a una oración comunitaria presidida fuera de la Santa Misa, o si se refieren también a una oración comunitaria presidida dentro de la celebración de la Santa Misa. Ambos textos ponen de manifiesto, sin lugar a mayor discusión, la plegaria dirigida a Dios que hacen los habitantes de la ciudad eclesial, quienes, en parte, componen la ciudad civil. Ellos imploran la óróvoı́ (concordia) entre los habitantes de la tierra y sus respectivos gobernantes, la cual está estrechamente relacionada con la virtud de la obediencia o sumisión ${ }^{27}$ a la autoridad civil, debido a que ella manifiesta la presencia de Dios. Oponerse a dicha autoridad es oponerse a la voluntad divina. Una idea relevante que subyace a los pasajes de $1 \mathrm{Clem}, 60,4$ y $1 \mathrm{Clem}, 61,1$ es la de Iglesia imitadora del orden civil romano.

La Iglesia, en cierto modo, reproduce dicho orden presentándose como organismo social análogo a la sociedad civil, ordenado bajo un claro principio de capitalidad que se ve reflejado en el culto. La estructura social al interno de la ciudad eclesial vela por la ónóvoıa, respetando el ordenamiento que Dios le ha dado; ordenamiento que también le concedió a la sociedad civil.

En segundo lugar, el término òjóvoı adquiere una nueva connotación teológica en la Prima Clementis. Esta aplica dicho vocablo a ciertos episodios de la historia de la salvación desplegados en distintos escenarios bíblicos. Estamos aquí ante una interpretación clementina de algunos pasajes bíblicos en los cuales ónóvoı apunta a la característica principal de la comunidad. En la narración sucinta de la historia de Noé -personaje que es un ejemplo de concordia- y una vez acontecido el caos diluviano, los animales se disponen a

251 Clem, 34, 7. Es bastante plausible el sitz im leben cultual que tiene este pasaje, reflejo de la práctica romana eucarística de los tiempos en que se escribió la Prima Clementis.

26 Los pasajes relevantes son: $1 \mathrm{Clem}, 60,4$. 1Clem, 61, 1.

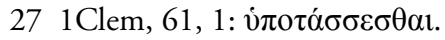


ubicarse en concordia dentro del arca. La naturaleza, que entra en desorden a través de la tempestad, recupera su concordia original en la figura de un arca concebida en modo de sociedad de animales (1Clem, 9, 4). El texto también relata una historia ya conocida por el cristianismo de la época: el episodio de la salida de Sodoma que involucra a Lot y su mujer, enfatizando que ella, a diferencia de su marido, no está en concordia con Dios, por lo que recibe un castigo junto a la merecida desgracia $(1 \mathrm{Clem}, 11,2)$. La imagen empleada apela al concepto de sociedad conyugal que no vive en consenso debido a que uno de sus miembros rompe la concordia con Dios.

En tercer lugar, la óróvoı es una forma de vida relacionada con el comportamiento. El cristiano al interno de la ciudad eclesial ha de vivir con un estilo cuya característica principal es la concordia. Esta lo compromete en la acción, por consiguiente, lo introduce en una ética: quien vive en la óuóvoı se involucra -según la Prima Clementis- con un tipo de acción que consiste en obrar lo que es bueno dentro de la ciudad eclesial:

Por tanto, unámonos a aquéllos a los que se les da la gracia de Dios. Revistámonos de concordia teniendo sentimientos de humildad, siendo dueños de nosotros mismos, alejándonos de toda murmuración y calumnia, siendo justos con obras y no con palabras $(1 \mathrm{Clem}, 30,3) .^{28}$

La concordia de las obras posibilita la concordia del amor en la ciudad eclesial. Nuestro texto afirma que "el amor todo lo hace en concordia". ${ }^{29}$

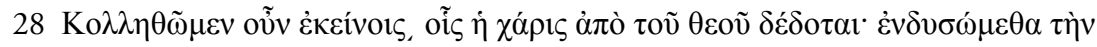

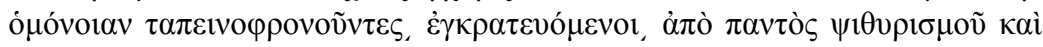

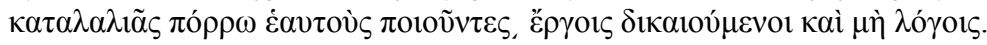
El texto entrelaza ó $\mu$ óvor $\alpha$ con el sustantivo है $\rho \gamma \alpha$. La idea principal del enlace entre ambos vocablos se puede formular con la expresión: 'la concordia de las obras'. El texto citado se refiere también a hombres que han recibido la gracia de Dios. Sin embargo, el relato no une el estado de gracia con el ejercicio de la concordia mediante las obras.

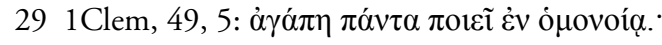

En la confección de esta frase, la Prima Clementis tiene en cuenta el himno del amor presentado por Pablo a los corintios (Cf. 1Corintios 13, 4-10), y agrega al

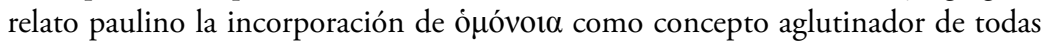
las bondades del amor. 
Lo que puntualmente añade la ómóvoı de la Prima Clementis al concepto paulino del amor es un matiz que complementa la idea del amor ad intra de la ciudad eclesial: esta ya no es simplemente una virtud individual que se exterioriza desde el corazón humano (1Corintios) sino una nota constitutiva de la ciudad eclesial en tanto organismo (Prima Clementis). Nuestro texto, en definitiva, plantea lo siguiente: allí donde existe la ónóvoı del amor, la ciudad eclesial vive; por el contrario, allí donde hay oróoıı, la ciudad eclesial muere o está en serio riesgo de muerte.

La concordia es fundamento de la ciudad eclesial del amor y se actualiza en la ciudad civil en la medida en que se vive como virtud ciudadana. La expresión clementina examinada: 'el amor todo lo hace en concordia' varía más adelante, en 1Clem, 50, 5, hacia el enunciado: 'concordia del amor ${ }^{30}$ con el mismo significado, ya que tanto la 'concordia del amor' como 'el amor que todo lo hace en concordia' encarnan, al interno del cuerpo social eclesial, aquel amor que se traduce en un hacer ${ }^{31}$, esto es, en un obrar. Para un cristiano dicho obrar indica una práctica de los mandamientos del Señor (Dios) ${ }^{32}$.

En cuarto lugar, la ójóvoı aparece en la Prima Clementis en modo de exhortación, invitación o consejo para superar la ơó́øıs. Lo ocurrido en esa Iglesia al momento en que se escribe el texto se sintetiza a partir de la expresión oráoıs, la cual más que expresión es un concepto o constructo inabarcable en un solo término, susceptible de ser traducido por varios vocablos: 'revuelta', 'desorden', 'rebelión', 'sedición', 'discusión', 'disensión'. Elijo 'discordia' entre todos los términos que se proponen como traducción de otó́øı..$^{33}$ La comunidad eclesial descrita en la Prima Clementis atestigua la existencia de una sorpresiva discordia entre los fieles de Corinto. ${ }^{34}$ Esta

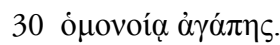

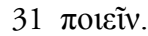

32 El texto de 1Clem, 50, 5 enlaza también con el de 1Clem, 30, 3 en el sentido práctico

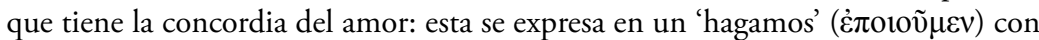

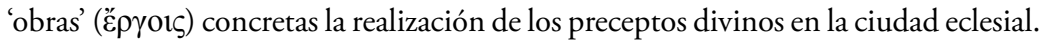

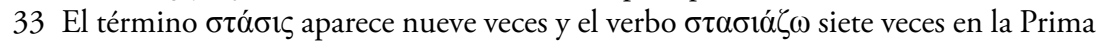
Clementis.

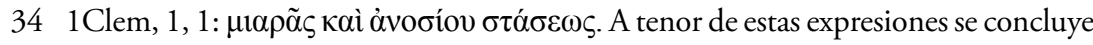
que la discordia de la Iglesia de Corinto es repulsiva y sacrílega, es decir, detestable. 
discordia es, según el parecer de los mismos corintios, 'detestable'35. Llama la atención el hecho que la comunidad eclesial de Corinto cambie en algún momento de su desarrollo espiritual la virtud por el vicio: de un tiempo a la fecha han surgido entre los miembros de esta Iglesia sentimientos opuestos a la ópóvoıa, tales como la disputa y la discordia. ${ }^{36}$ Según el texto anterior un grupo compuesto por personas jóvenes entró en discordia con los miembros de edad avanzada produciéndose en la ciudad eclesial de Corinto una otáoıs de los 'jóvenes contra los ancianos'. ${ }^{37}$ ¿Quiénes son los ancianos del texto? Al respecto tenemos dos tipos de explicación, complementarias y no opuestas.

La primera, afirma que los ancianos son aquellos sujetos mayores de edad que integran la ciudad eclesial de Corinto. En conformidad con esta interpretación la expresión citada de $1 \mathrm{Clem}, 3,3$ se refiere a una discordia generacional en la Iglesia de Corinto, es decir, a una discordia entre los que tienen pocos ańos de vida y las personas mayores en edad. A partir de esta explicación se puede sostener lo siguiente: la oróoıs a la que se refiere la Prima Clementis consiste en una ruptura de la ómóvoı en la comunidad eclesial de Corinto entre jóvenes y ancianos, personajes estos últimos con un importante desempeño en la conducción de la Iglesia primitiva en el contexto de la familia en tanto célula básica de la ciudad eclesial. En efecto, alrededor del año 100 d.C. impera en las comunidades cristianas de Roma y Corinto un ambiente eclesial realizado principalmente dentro del marco de las familias, las que constituyen tanto el núcleo de la sociedad como el de la Iglesia en aquella época. El cristianismo de los inicios se desarrolla fundamentalmente en los hogares, esto es, en la así llamada 'iglesia doméstica'. ${ }^{38}$

Los ancianos de la comunidad familiar, tanto en el aprendizaje de la virtud como en el de las enseñanzas religiosas cristianas más específicas,

351 Clem, 2, 6: $\beta \delta \varepsilon \lambda \nu \kappa \tau$ ćs. Esto significa que tanto el cisma como la discordia no forman parte del modo de actuación habitual de la comunidad eclesial de Corinto.

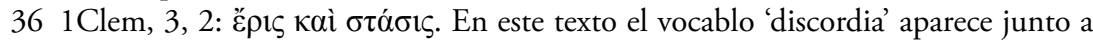
'disputa', por lo tanto, una vez surgida la disputa al interno de la comunidad (ciudad) eclesial, inmediatamente asoma la discordia entre sus miembros.

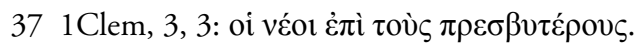

38 La expresión 'iglesia doméstica' se entiende en la presente investigación como 'ciudad eclesial doméstica'. 
desempeñan un papel protagónico en la ciudad eclesial de Corinto. Ellos, en el ámbito de la ónóvoıa, velan por la promoción de lo que más conviene a la comunidad familiar en aquellos asuntos que pueden ser de otra manera, convirtiéndose en guías adecuadas respecto de sus propios parientes. En dicha labor los ancianos fueron acompañados por mujeres, quienes al interno de sus comunidades familiares naturales enseñaron también la virtud. Los ancianos se involucraron en una otóoıৎ con personas jóvenes en el seno de sus respectivas familias, discordia que consiste en un desacuerdo generacional en el clima de una lucha de intereses, cuya naturaleza específica no es aclarada por el texto. El pasaje de $1 \mathrm{Clem}, 51,1$ da cuenta desde el punto de vista literario de la trama histórica descrita: algunos jóvenes al interno de su núcleo familiar fueron débiles en la práctica de la ónóvoı haciéndose partícipes de los sentimientos de oráoıs. Entonces, el autor del texto exhorta a pedir perdón por ellos, cuales provocadores de la discordia, a la vez que pide oraciones por aquellos que siguen a los jóvenes en sus inexcusables sentimientos.

La segunda explicación del vocablo 'ancianos' en la Prima Clementis se refiere a los miembros de un consejo directivo de presbíteros en la ciudad eclesial de Corinto. ${ }^{39}$ No existe una razón histórica suficiente para pensar que este consejo funcionaba en los últimos ańos del siglo I d.C. solamente en la ciudad eclesial de Corinto. A dicho consejo le corresponde en esa época dirimir problemas en torno a diferencias de opinión que no alcanzan un consenso previo. Por tanto, este consejo es la instancia superior de la óróvoıa y su empeńo máximo, según el alcance que le proporciona el texto de la Prima Clementis, consiste en zanjar una cuestión en el ámbito de la disciplina para impedir cualquier tipo de otóoıs. La ciudad eclesial en su conjunto, con una base en las familias naturales que abrazan la fe cristiana, debe alcanzar la concordia mediante el diálogo y el consenso en aquello que puede ser observado de diversas maneras.

No hubo acuerdo entre los jóvenes y los ancianos al interno de las familias cristianas de Corinto, tampoco el Consejo presbiteral de la ciudad eclesial de Corinto pudo resolver satisfactoriamente el problema. Ante la

39 El sustantivo plural 'ancianos' puede ser traducido por 'presbíteros'. 
falta de un acuerdo se pidió la colaboración en la solución del asunto a los presbíteros miembros del Consejo de Roma, quienes en modo exhortativo y no deliberativo colaboraron con dicha solución. La Prima Clementis una vez más es parca en la información. Dice simplemente que la oróoıs eclesial en Corinto es 'persistente'.$^{40}$ El Consejo presbiteral de la ciudad eclesial de Roma no impuso en la solución del conflicto un modo de actuar, sino más bien sugirió la acción más conveniente conforme a la recta razón, proporcionando un camino a seguir para la solución definitiva del conflicto. Dicho camino, probablemente, fue aceptado por el consejo de presbíteros de Corinto y presentado para ser dirimido al interno de las familias cristianas, las cuales se inclinaron en su mayoría por la aceptación de la propuesta del Consejo presbiteral de Roma. La propuesta deliberada con un consenso de mayoría volvió al Consejo presbiteral de Corinto y este la impuso a toda la comunidad como norma a seguir.

El texto de la Prima Clementis no habla expresamente de lo que acabo de exponer, pero si se refiere de modo explícito a los miembros que siguen pensando en una solución diferente del conflicto una vez zanjada la cuestión. Ellos tienen dos caminos posibles a elección. La primera senda -en el orden de aparición dentro del texto- es el exilio voluntario. La restitución de la concordia pasa, necesariamente, por la exclusión de la comunidad de aquellos protagonistas de la oróøı que no están de acuerdo con la solución que se dio al problema. ${ }^{41} \mathrm{Su}$ salida de la comunidad se realiza en virtud de una libre decisión. El relato de la Prima Clementis señala algunos ejemplos de gentiles, tales como reyes y jefes, que en tiempos de calamidad optaron por marcharse de sus propias ciudades con el objetivo de poner fin a una

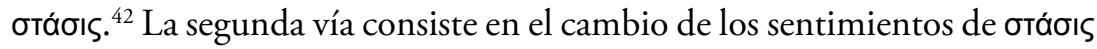
por una obediencia sumisa a los presbíteros, o sea, al dictamen de aquellos

40 1Clem, 46, 9: غ̇ंínovos.

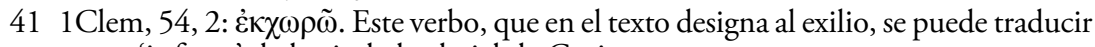
como 'ir fuera' de la ciudad eclesial de Corinto.

$421 \mathrm{Clem}, 55,1$. Ciertos exilios voluntarios, tales como aquellos que encontramos en Grecia o en la Roma antigua, son verdaderos ejemplos de una exclusión razonable cuando está en juego la integridad de una unidad mayor, por ejemplo, la patria. 
que componen el consejo de la ciudad eclesial de Corinto. ${ }^{43}$ Quienes no están de acuerdo deben deponer su punto de vista asumiendo que su posición no es la mejor ni la más conveniente para la ciudad eclesial a la luz de la recta razón, ya que se opone a un dictamen presbiteral que ha recogido el parecer de la mayoría de los cristianos de Corinto. ${ }^{44}$

La concepción subyacente al pensamiento descrito en las líneas anteriores es la de comunidad eclesial en cuanto organismo vivo. En efecto, la Iglesia que describen los textos acerca de la oтóoı en Corinto posee la fisonomía de un verdadero cuerpo social al modo de una societas. Esta es un totus visible. Sus partes constitutivas ocupan lugares definidos con roles específicos y en tareas complementarias. La totalidad funciona por el aporte de las partes individualmente consideradas y bien trabadas entre sí, al punto que, en el cuerpo de la Iglesia, somos miembros los unos de los otros. La vida al interno de este cuerpo eclesial se rige por la ónóvoı del amor, razón por la cual toda clase de oráoıs carece de sentido. ${ }^{45}$

El texto de la Prima Clementis, bajo este punto de vista, es un ejercicio de fraternidad eclesial en el que se busca convencer a los cristianos de Corinto, a través de una retórica persuasiva, de la importancia que tiene el diálogo deliberativo en la ómóvoı eclesial. El carácter exhortativo del documento

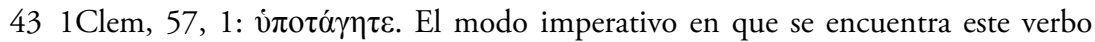

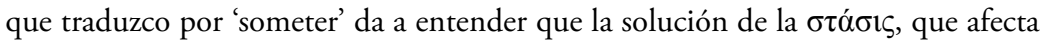
a la ciudad eclesial de Corinto, consiste en cumplir con el mandato de sumisión al Consejo de presbíteros. La actitud contraria es aquella que aparece en 1Clem, 47,

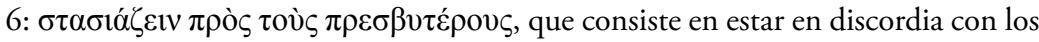
presbíteros que componen el Consejo de Corinto.

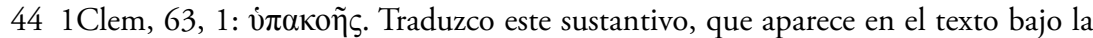
forma de genitivo singular, por 'obediencia', clave en la descripción de la actitud

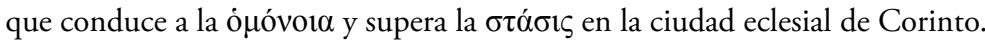

45 Respecto a lo que se acaba de decir son dos los textos más importantes de la Prima Clementis. El primero, corresponde al pasaje de 1 Clem, 46, 7, en el que se utiliza la expresión: 'somos los unos miembros de los otros'. Esta recuerda la consistencia

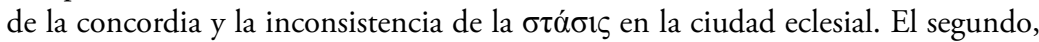
ubicado en 1Clem, 49, 5, muestra la constitución fundamental de la ciudad eclesial basada en la concordia del amor. Para quienes viven en dicha concordia no hay lugar

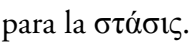


que invita a un diálogo deliberativo se muestra en el tono que su autor, miembro del consejo de presbíteros de Roma, emplea para dirigirse a los corintios: utiliza varias veces imperativos, pero también abundan en el escrito expresiones de corte fraterno cuyo objetivo es seducir y convencer a los corintios de que practiquen la tan anhelada ójóvoı́. Hacia el final del escrito nos encontramos con el verbo 'recordar' que aparece en relación precisamente con el carácter exhortativo (consejo) del texto: la Prima Clementis no habla acerca de imponer la ónóvoı́ sino de traerla a la memoria de los corintios. El escrito se orienta hacia la toma de conciencia de los corintios en aquella ónóvoı que les "hemos recordado". ${ }^{46}$ Se trata de un recuerdo activo, esto es, actualizado en el aquí y ahora de su vida eclesial. El texto afirma que es bueno acordarse de la ójóvoı́, porque esta es parte fundamental de la existencia de la Iglesia. En este sentido, el documento es un recordatorio de valores, siempre antiguos y siempre nuevos, de la constitución de la Iglesia como organismo vivo. ${ }^{47}$

\section{Conclusiones}

La Prima Clementis utiliza los vocablos ópóvoı y oтáoı en la línea de la filosofía política de ciertos textos de la Ética a Nicómaco y Ética Eudemia. Dicha cercanía permite sostener como hipótesis que el autor de la Prima Clementis tuvo un contacto con la obra de Aristóteles en los dos tratados mencionados. Tal como se muestra en (Pardo, 2019, p. 1-23) el enlace entre los textos de Aristóteles y la Prima Clementis es Quintiliano de Calahorra, autor del proyecto educativo romano.

Tanto en la ciudad griega descrita por Aristóteles como en la comunidad de Corinto referida por la Prima Clementis, el hombre se orienta hacia el desarrollo de la amistad natural con sus semejantes. La Iglesia de Corinto, no totalmente equiparable a la ciudad aristotélica, imita dicha ciudad en

46 1Clem, 62, 3: vं $\varepsilon \varepsilon \mu v \eta ́ \sigma \alpha \mu \varepsilon v$.

47 En la línea de lo dicho hay que leer en conjunto los siguientes pasajes: 1Clem, 62, 2. 3; 1Clem, 63, 2; 1Clem, 65, 1 . 
la realización de la ónóvoıa, aconsejable como forma de vida comunitaria. La ópóvoı́, tanto en el pensamiento de la Prima Clementis como en el de Aristóteles, se vive a partir del consenso. Esto implica la búsqueda de lo mejor y lo más conveniente para todos a la luz de los dictámenes de la recta razón. En la ciudad como en la Iglesia, el hombre experimenta el desafío de vivir en sociedad desde la ónóvoı́, ejercitando la deliberación mediante el diálogo y aprendiendo la sumisión a la instancia superior de discernimiento, eco de la decisión mayoritaria.

\section{Referencias}

Aristóteles (1972ss.). Aristoteles Phil. et Corpus Aristolelicum, Ethica Nicomachea (EN) Ethica Eudemia (EE). En: Thesaurus linguae gracae (TLG). Edición digitalizada de textos escritos en griego desde Homero hasta la caída de Bizancio en el año 1453. Irvine: Universidad de California.

Aristóteles (1985). Ética Nicomaquea. Ética Eudemia. Trad. (J. Pallí Bonet, trad.). Madrid: Editorial Gredos.

Bakke, O.M. (2001). "Concord and Peace": A rhetorical analysis of the first letter of Clement with an emphasis on the Language of unity and sedition. Tübingen: JCB Mohr (Paul Siebeck).

Blanco, E.C., y Parrado, M.P. (2018). Ética, política y justicia como fundamentación antropológica del derecho natural clásico. Revista de la Academia Colombiana de Jurisprudencia, (367), 105-122.

Borisonik, H. (2011). Ergón y areté en la filosofía política de Aristóteles. Problemata: Revista Internacional de Filosofia, 2(2), 99-114.

Bueno, M. (2018). Aristotle and the citizen. Tópicos. Revista de Filosofia, (54), 11-45.

Cadavid, I. (2011). La concordia o amistad civil: Un presupuesto de la virtud política en Aristóteles. Ratio Juris, 6(12), 63-72.

Covarrubias, A. (2000). La persuasión de las mayorías según Aristóteles. Onomázein, 5, 271-286.

Clemente de Roma. (1994). Clemente de Roma. Carta a los corintios. Homilia anónima (Secunda Clementis). Trad. J. Ayán, Trad. Madrid: Ciudad Nueva. 
de Mesa, J.A.L. (2012). La comunidad humana (polis) como condición de la libertad en la ética aristotélica. Estudios Políticos, (41), 189-199.

Farrés, O. (2015). La amistad cívica en Aristóteles: concordia y fraternidad. Anales del Seminario de Historia de la Filosofía, (32), 41-67.

Gallardo, J. (2009). Elogio modesto a la deliberación política. Revista Uruguaya de Ciencia Politica, 18(1), 85-115.

Garcés Giraldo, L.F., y Giraldo Zuluaga, C. (2014). La continencia aristotélica: encauzamiento de las acciones rectas en el científico que experimenta con animales. Civilizar Ciencias Sociales y Humanas, 14(26), 199-210.

Giraldo, L.F.G., Díaz, O.H., y López, A.P.A. (2017). El amigo en Aristóteles como posibilidad de autoconocimiento y las diferencias con un adulador. Revista Lasallista de Investigación, 14(2), 192-202.

Godoy, O. (2012). La democracia en Aristóteles. Los orígenes del régimen republicano. Santiago de Chile: Ediciones Universidad Católica de Chile.

Gómez, C.E.B. (2017). Del “animal político” a la “amistad política”. Una perspectiva aristotélica. Teoría y Praxis, (30), 101-120.

Martí, M. (2017). Amistad y reconocimiento. Sobre la philia aristotélica. Lo que Aristóteles vio y Hegel pasó por alto. Contrastes. Revista Internacional de Filosofía, 22(3), 37-49.

Martín, J.P. (1994). La cultura romana y la Prima Clementis. Observaciones de contenido y de método. Teología: revista de la Facultad de Teología de la Pontificia Universidad Católica Argentina, (63), 55-72.

Morales, F. (2003). Libertad y deliberación en Aristóteles. Ideas y valores, 52(121), 81-93.

Motto, A. (2013). La caridad como amor de amistad. Teología, 50(112), 21-53.

Pardo, F. (1988). El concepto de unidad en la carta de Clemente a los Corintios. (Tesis para optar al grado de Licenciado en Teología). Santiago: Pontificia Universidad Católica de Chile.

Pardo, F. (2019). Análisis de 1Clem 19,2.20, 1-10: conexiones y diferencias. Theologica Xaveriana, 69 (187), 1-23.

Prinzivalli, E. (2009). La Prima Lettera di Clemente: La ambiguità di un conflitto. Annali di storia dell' esegesi, 26 (1), 23-46. 
Influencia de algunos aspectos de la filosofía política de aristóteles en la Prima Clementis

Sánchez, N. (2018). Democracia, concordia y deliberación pública en la Política de Aristóteles. Logos An. Sem. Met., (51), 35-56.

Valencia, F.M. (2018). En torno a la amistad. Revista de Filosofía, 9(1), 11-16.

Zamora, J. M. (2001). Sofía y Phrónesis en Aristóteles: Ética a Nicómaco VI, 7, 1141 a 8-1141 b 22. Taula: quaderns de pensament, 35, 37-52. 
